\title{
Editorial
}

\section{Conundrum of Research Publication in India}

\author{
SUBHASH C LAKHOTIA*
}

Editor-in-Chief, and Cytogenetics Laboratory, Department of Zoology, Banaras Hindu University, Varanasi 221005 , India

One of the essential components of creative activities carried out by academia in institutions of higher learning is to publish results of their research so that the community at large may know, evaluate and appreciate the new findings and the resulting advance in knowledge/understanding. Besides this 'altruistic' as well as self-satisfying reason for research publication, another reason that has acquired greater importance, and justifiably so, is that the research output, measured in terms of published research, is taken as a major determinant for assessment for hiring, subsequent promotions and awards/recognitions. However, the apparently simple-looking task of publishing and sharing of one's new research findings is becoming increasingly complicated, puzzling and even frustrating to authors as well as readers, more so to those in a country like India which has witnessed a remarkable spurt in research and publication activities in the 21 st century.

The increasing numbers of researchers in different fields of enquiry and the consequent increase in numbers of journals where one can publish are placing heavier demands on time of those who are involved in the evaluation process. In order to ease this pressure, and ostensibly to reduce the individual biases on parts of the evaluators, a variety of scientometric or bibliometric parameters have been formulated and used to provide a rapid and objective assessment of the significance of research output of an individual or an institution. However, it is now widely recognized that the bibliometric parameters when used in isolation can indeed be very misleading. One such example is the journal 'impact factor'. Besides failing to assess the real quality of the published work, the vicious circle created by the misplaced importance ascribed to the journal impact factor has adversely affected research journals published from India and other 'less-developed' countries. An unfortunate consequence of this has been the differential credit assigned by various agencies in India to papers published in the so-called 'national' and 'international' journals.

In addition to being centres for dissemination of knowledge, the institutions of higher learning (colleges and universities) are also expected to generate new knowledge through research. In order to promote involvement of faculty in colleges and universities in India in active research, the University Grants Commission (UGC) decided to provide incentives based on research publications for appointments and promotions. As a next step, to ensure that the faculty does participate in research, certain minimal numbers of research publications have been defined as mandatory eligibility criteria. Similar pressure on research publications has been evident during the past few decades all over the globe. Exploiting the pressure of 'publish or perish' atmosphere, and realizing that quantity rather than quality has become more important in the job market, large numbers of unscrupulous 'predatory' publishers have sprung up all over the world, more so in India and other developing countries, which have a larger population competing for fewer opportunities. With a view to ensure some quality in research publications, the UGC came out with the idea of listing journals that should be considered by the various academic institutions as legitimate 'research journals'. As may be expected in the current commercial-interest dominated scenario of research publications across the globe, a large number of substandard journals or those published by transparently unscrupulous publishers found their way to get included in the UGC-list. Recognition of publications 
in such journals has not only resulted in appointments/ promotions of undeserving candidates, it has also heightened the bias that researchers from less known institutions in India have to often face when their legitimate research findings are submitted to established journals outside the country. Following periodic protests from sections of the academic community, the UGC has been going through repetitive cycles of inclusion and exclusion of journals in its 'official' list. Such a fluid situation obviously leaves researchers, especially the young and lessexperienced ones, confused not only about what to publish but more importantly about where to publish.

The confusion and frustration generated by the prevailing conditions about where to publish and what to publish is further compounded in India and other similarly placed countries by the continuously escalating costs of publications. In the present era of commercialization of research journals, the charges to be paid by authors (or their host institutions) on account of publications costs place researchers from less-endowed institutions at a serious disadvantage. The so-called 'open access' charges add to the woes of researchers at universities and colleges because of the very limited availability of funds and basic infrastructure for research.

The prevailing conundrum of research publication in the country has affected the quality of research and its assessment, and at the same time has also seriously affected healthy growth of research journals in India. In this background, it is significant that the Indian National Science Academy has adopted a policy about assessment of research contributions of individuals and institutions in the country (see pp. 319-329 in this issue). It is hoped that the various regulatory and funding agencies would seriously examine and adopt these recommendations so that the assessment becomes more objective. This would help researchers in undertaking more serious and indepth investigations rather than worry only for numbers. 